\title{
Article
}

\section{Influence of loneliness and rejection sensitivity on threat sensitivity in romantic relationships in young and middle-aged adults}

Nowland, Rebecca, Talbot, Rebecca and Qualter, Pamela

Available at http://clok.uclan.ac.uk/23050/

Nowland, Rebecca ORCID: 0000-0003-4326-2425, Talbot, Rebecca and Qualter, Pamela (2018) Influence of loneliness and rejection sensitivity on threat sensitivity in romantic relationships in young and middle-aged adults. Personality and Individual Differences, 131 . pp. 185-190. ISSN 0191-8869

It is advisable to refer to the publisher's version if you intend to cite from the work. http://dx.doi.org/10.1016/j.paid.2018.04.047

For more information about UCLan's research in this area go to http://www.uclan.ac.uk/researchgroups/ and search for <name of research Group>.

For information about Research generally at UCLan please go to http://www.uclan.ac.uk/research/

All outputs in CLoK are protected by Intellectual Property Rights law, including Copyright law. Copyright, IPR and Moral Rights for the works on this site are retained by the individual authors and/or other copyright owners. Terms and conditions for use of this material are defined in the policies page. 
Loneliness, RS and RTS in romantic relationships

Influence of loneliness and rejection sensitivity on threat sensitivity in romantic relationships in young and middle-aged adults

Author Accepted Manuscript

Other: Nowland, R., Talbott, R. \& Qualter, P. (in press). Influence of loneliness and rejection sensitivity on threat sensitivity in romantic relationships in young and middle-aged adults. Personality and Individual Differences.

This is the author accepted manuscript. It is advisable to refer to the publisher's version of the paper if you intend to cite from the work. 
Loneliness, RS and RTS in romantic relationships

\begin{abstract}
There are individual differences in sensitivity to threats, but no research has examined risk factors for threat sensitivity in romantic relationships (RTS). Both loneliness and rejection sensitivity are associated with threat sensitivity, but no studies have examined whether these factors are associated with RTS in particular. The current study examined the influence of loneliness and rejection sensitivity (RS) on RTS in two cohorts: 18-35 ( $\mathrm{n}=166)$ and over 35 year olds $(\mathrm{n}=153)$. We examined relationships between the variables, but also examined whether RS had mediating and/or moderating effects on the relationship between loneliness and RTS. Results showed (1) loneliness and RS were positively associated with RTS, (2) RS mediated the relationship between loneliness and RTS, (3) loneliness was higher in the older group, and (4) for women loneliness was not dependent on relationship status, but men were lonelier and more sensitive to rejection if they were not in a romantic relationship. The results indicate that those who are lonely and higher on rejection sensitivity may need support in their romantic relationships to avoid a hypersensitivity to threats; this is particularly important for men, whose loneliness and RS were dependent on relationship status.
\end{abstract}

Key words: Loneliness, rejection sensitivity, romantic relationships, relationship threat sensitivity, relationship incentive sensitivity 
Loneliness, RS and RTS in romantic relationships

1. Introduction

Being socially connected increases feelings of togetherness, yet we are also capable of feeling threatened in the same social groups in which we seek solace. Being aware of social threats is adaptive because it promotes rapid processing of threat- or fear- related stimuli and prevents behaviour that may result in rejection (Eisenberger, 2013). However, some people can become over-sensitive to threat, resulting in people perceiving more negative social information, withdrawing from social interaction and having difficulties connecting with others and maintaining relationships. Both loneliness and rejection sensitivity (RS) have been associated with threat sensitivity (Berenston et al., 2009; Burkland, Eisenberger, \& Lieberman, 2007; Dewitte \& De Houwer 2008; Spithoven, Bijttebier, \& Goossens, 2017), but no research has examined whether those factors influence threat sensitivity in romantic relationships in particular. It is important to examine risk factors for threat sensitivity in romantic relationships to identify people who are more likely to have difficulties with intimate relationships and determine appropriate strategies to support them.

\subsection{Threat sensitivity in romantic relationships}

In close relationships people are generally motivated to have approach related behaviour (i.e. towards intimacy and growth) towards incentives and avoidance behaviour to threats (i.e. away from conflict and rejection; Gable \& Impett, 2012). Perceived threats in a relationship typically change a person's behaviour from incentive-approach orientated behaviour to threat-avoidant orientated behaviour (Cavallo, Fitzsimons \& Holmes, 2010). But some people can become over-sensitive to threats. Laurenceau, Kleinman, Kaczynski, 
Loneliness, RS and RTS in romantic relationships

and Carver (2010) developed the Relationship Incentive and Threat Sensitivity Scale which has two components: Relationship Incentive Sensitivity (RIS) and Relationship Threat Sensitivity (RTS). People who have high RIS are driven to connect with their partner, move the relationship forward and enhance the quality of the relationship, whereas people who have high RTS are more negative and anxious about the relationship and worry about its future, focusing on negative interactions/events. When people deal with a relationship in a way that focuses on incentives rather than threats, people are more likely to overcome difficulties with relationships and deal with conflicts constructively. What is missing from the current literature is an examination of factors that influence whether people are driven by incentives or are overly sensitive to threats in romantic relationships. Examining factors that impact threat sensitivity in romantic relationships will explain why some people behave in a negative and avoidant way in relationships and will be helpful for counsellors and/or clinical psychologists supporting people to overcome difficulties with formation and maintenance of personal relationships.

\subsection{Rejection Sensitivity and Threat Sensitivity}

Rejection sensitivity has been associated with threat sensitivity and is characterised by a tendency to anxiously expect rejection, an increased perception of rejection, and an overreaction to it (Downey \& Feldman, 1996). Laboratory studies have shown that RS is associated with an avoidance of social threat stimuli (Berenston et al., 2009; Dewitte \& De Houwer 2008) and increased neural activation to disapproving facial expressions (Burkland et al., 2007), indicating threat sensitivity. Only one study has examined the influence of RS on RTS and found a moderate, but non-significant, association in their sample of 50 romantic couples (Laurenceau et al., 2010). A weakness of that study is the sample size, which may 
Loneliness, RS and RTS in romantic relationships

account for the lack of significance, despite a moderate association, so replications with a larger cohort are necessary.

\subsection{Loneliness and Threat Sensitivity}

Loneliness has also been associated with threat sensitivity and is defined as a subjective experience in which a person experiences a deficit in social and emotional ties to others (Perlman, \& Peplau, 1981). Cacioppo and Hawkley (2009) proposed that the maintenance of loneliness is a result of hyperviligance to social threat, and empirical work supports that thesis (for a review see Spithoven et al., 2017).

It is important to examine the impact of loneliness on threat sensitivity in romantic relationships in particular because, despite loneliness being lower in those with a romantic relationship, studies have shown that individuals report feeling lonely even if they are married (Tornstam, 1992) and that there is a negative association between relationship quality and loneliness (Deniz, Hamarta \& Ari, 2005; Green, Richardson, Lago, \& Schatten-Jones, 2001; Flora \& Sergin, 2000). Lonely people have been shown to display inappropriate jealousy in romantic relationships (Rotenberg, Shwechuk \& Kimberley, 2001) and relational aggression (Strouch, Bagner, Geffken \& Baumeister, 2004). Threat sensitivity in romantic relationships may explain why people remain lonely despite having a romantic relationship and explain the inappropriate jealousy and relational aggression that is associated with loneliness.

Loneliness may have a direct impact on threat sensitivity in romantic relationships, but RS may be the mechanism that links loneliness to threat sensitivity in relationships 
Loneliness, RS and RTS in romantic relationships

because loneliness is associated with RS (London, Downey, Bonica, \& Paltin, 2007; Watson \& Nesdale, 2012).

1.4. The current study

The current study addresses the gap in the literature for an examination of the role of risk factors for threat sensitivity in romantic relationships by investigating whether loneliness and RS impact on levels of RTS. It is predicted that both loneliness and RS will be associated with RTS, and that RS may affect the strength (moderation effect) and/or account for (mediation effect) the relationship between loneliness and RTS. We also examined the influence of age on RTS because older adults are better at regulating their emotions (Urry \& Gross, 2010), predicting feelings of emotional arousal (Nielsen, Knutson, \& Cartensen, 2008) and reappraising negative emotions (Silvers et al., 2012), than their younger counterparts; so older adults may be better at regulating threat-related responses. Gender differences are also examined because women are more likely to make use of same-sex friendships for emotional sharing and support (Aries \& Johnson, 1983; Caldwell \& Peplau, 1982) than men, so the role of a romantic relationships for providing emotional support is higher in men and may result increased RTS.

2. Method

2.1 Participants \& Procedure

Participants were recruited from student and staff population at two universities in North West England $(\mathrm{N}=319$, Mage $=31$ years, $\mathrm{SD}=12.62,64 \%$ female, $67 \%$ in a romantic relationship). To increase participation, 37 participants (11.6\%) completed the questionnaire on-line; all 
Loneliness, RS and RTS in romantic relationships

others completed the questionnaire on paper (completing the questionnaire online did not have an impact on the findings, i.e. separate analysis of this sub-group revealed similar results). For data analysis purposes, participants were grouped into 18-34 year olds ( $\mathrm{N}=166$, Mage $=22.58$, $\mathrm{SD}=4.71,63.2 \%$ females, $53.6 \%$ in a romantic relationship) and over 35 year olds $(\mathrm{N}=153$, Mage $=45.84, \mathrm{SD}=6.70,66.3 \%$ females, $82.2 \%$ in a romantic relationship).

\subsection{Measures}

\subsubsection{Loneliness.}

Loneliness was measured using the R-UCLA loneliness scale (Russell, 1996). Participants were asked to rate 20 statements about how they usually feel, e.g."I feel in tune with the people around me” on a scale of 1 (never) to 4 (often). After reverse scoring some of the statements, loneliness scores were calculated by summing all statements. $\alpha=.92$.

\subsubsection{Rejection sensitivity}

The shortened version of the Rejection Sensitivity Questionnaire (RSQ; Downey \& Feldman, 1996) was used. It includes 8 scenarios that may result in rejection, e.g. "You approach a close friend to talk after doing or saying something that seriously upset him/her” Each scenario is followed by two six-point scales: (1) rejection concern (6 = very concerned and $1=$ very unconcerned) and (2) acceptance expectancy (6 = very likely and 1 = very unlikely). Rejection concern is multiplied by acceptance expectancy (reversed) and averaged across the scenarios. 
Loneliness, RS and RTS in romantic relationships

Three of the scenarios in this measure were removed to avoid overlap with RTS because they specifically related to RS in romantic relationships. The remaining 5 scenarios were used in all the analyses. $\alpha=.83$.

\subsubsection{Threat sensitivity in romantic relationships}

Relationship Incentive and Threat Sensitivity Scales (RITSS; Laurenceau et al., 2010) were used. The RITSS was designed to be completed by those in a romantic relationship, so in the current study we included a question regarding whether the participant was currently in a romantic relationship. Participants not in a relationship were asked to imagine how they would feel if they were and complete the measure thinking about that imagined relationship. The measure comprises 11 statements (6 relate to RIS and 5 relate to RTS), e.g. "I go out of my way to be connected to my romantic partner" (RIS) and "Criticism and scolding from my romantic partner hurts me quite a bit” (RTS). Participants are asked to respond to how true the statement is to them on a scale of 1 (very false) to 4 (very true). $\alpha=.85$ (RIS) and .82 (RTS).

3. Results

3.1 Relationships between loneliness, RS, RIS and RTS

\subsubsection{Correlation and multiple regression analysis}

Descriptive statistics by age group and relationship status are presented in Table 1 and correlations among variables in Table 2. Loneliness was positively associated with RTS and RS. Rejection sensitivity was also positively associated with RTS. There were no 
Loneliness, RS and RTS in romantic relationships

associations between RIS and loneliness or $\mathrm{RS}^{1}$. To examine factors that influenced RTS, a multiple regression analysis was conducted (Table 3). Rejection sensitivity was an influence of RTS in the model, but not loneliness.

\subsubsection{Moderation and Mediation analyses}

A moderation analysis was undertaken to assess whether loneliness and RS interact to influence levels of RTS (Table 4). Variables were centred prior to multiplication. A hierarchical regression was conducted, entering the main effects first (loneliness and RS) and interaction term (loneliness $\mathrm{x}$ RS) at the second step. There was not a significant moderation effect.

An analysis using structural equation modelling was conducted to assess whether RS mediated the relationship between loneliness and RTS (Figure 1). Using a causal method (Baron \& Kenny, 1986) a mediation effect was evident because the direct effect between loneliness and RTS was reduced in model and was significant. Mediation was also tested using a bootstrap estimation approach with 5000 samples (Hayes, 2009; Shrout \& Bolger, 2002). This is considered to be a more valid and reliable method for small sample sizes and/or when multivariate normality cannot be met (MacKinnon, Lockwood, \& Williams, 2004). The true indirect effect was estimated using AMOS to lie between 0.66 and 0.19 with $95 \%$ confidence $(\beta=.13, \mathrm{SE}=0.03)$. Because zero is not in the $95 \%$ confidence interval, the indirect effect was significantly different from zero indicating a mediation effect.

\subsection{Gender and age-related differences}

\footnotetext{
${ }^{1}$ Correlation analysis was conducted separately for the group $(n=37)$ completing the questionnaires online to gauge whether that data could be merged with data completed offline and similar associations were found (i.e. loneliness was positively associated with both RTS $(r=.35)$ and RS $(r=.69)$ but not RIS $(r=-.05)$. RS was also not associated with RIS ( $r=-.01)$ but was associated with RTS $(r=.36)$.
} 
Loneliness, RS and RTS in romantic relationships

Gender and age related differences were examined using a series of 2 (gender) x 2 (age) $\mathrm{x} 2$ (relationship status) ANOVAs for each of the study variables, with all main effects and significant interactions reported in Table 1. There were significant main effects for age and gender for loneliness only. Loneliness was higher for those not in a relationship and in the older age group

For loneliness, a significant interaction for gender x relationship status was evident. Post hoc examinations showed that for females there were no differences in loneliness whether in a relationship or not $(\mathrm{t}(203)=0.45, \mathrm{p}=653)$, but males were lonelier if there were not in a romantic relationship $(\mathrm{t}(110)=3.75, \mathrm{p}<.001)$. Thus, for women, loneliness may be less about being in an intimate relationship than for men.

For RS a significant interaction for age $\mathrm{x}$ gender $\mathrm{x}$ relationship status was evident. Further analysis revealed that there were no differences in RS whether in a relationship or not in the younger group, but, for the 35+ group, RS was higher when not in a relationship $\left(\mathrm{F}(1,147)=5.38, \mathrm{p}=.022, \mathrm{\eta}_{\mathrm{p}}{ }^{2}=.04\right)$. In the older age group post hoc tests revealed no difference in RS for females whether in a relationship or not $(\mathrm{t}(93)=0.06, \mathrm{p}=.952)$, but when not in a relationship, RS was higher for males $(\mathrm{t}(19.53)=3.49, \mathrm{p}=.002)$. This indicates that in the older age group RS is more of a concern when single for men.

For RIS a significant interaction for age $\mathrm{x}$ relationship status was evident. Post hoc tests revealed that the 18-35 year group had higher RIS when in a relationship (Mean $=3.48$, $\mathrm{SD}=0.44)$ than when not in a relationship (Mean $=3.26,(0.60), t(162)=2.71, \mathrm{p}=.007)$. In the older age group, there was no difference in RIS between those in a relationship (Mean = 3.32, $\mathrm{SD}=0.56)$ than those not in a relationship $($ Mean $=3.42(0.46) \mathrm{t}(148)=0.79, \mathrm{p}=.433)$. For those in a relationship, the 18-35 year old group had higher RIS than the 35+ year old group $(18-35$ mean $=3.48(0.48), 35+$ mean $=3.33(0.56)-t(209)=2.12, p=.035)$; there was no difference in age groups for those not in a relationship $t(101)=1.25, p=.214$ ). These 
Loneliness, RS and RTS in romantic relationships

results indicate that the younger participants were more likely to be motivated to improve connection with their partner if they are in a relationship than older participants.

\section{Discussion}

The current study aimed to address the gap in extant literature for an examination of risk factors for threat sensitivity in romantic relationships and showed that both loneliness and rejection sensitivity are associated with relationship threat sensitivity. Rejection sensitivity was shown to a mechanism that links loneliness to relationship threat sensitivity.

\subsection{Loneliness and rejection sensitivity}

Loneliness was associated with RTS in the current study, indicating that lonely people in an existing or newly forming romantic relationships may need support to avoid focussing on negative events and ignoring conflicts in a relationship. Similar to previous findings of a moderate association between RS and RTS in a small sample (Laurenceau et al, 2010), the results of the current study in a larger sample also showed that rejection sensitivity was associated with RTS. In the current study RS was shown to be a mechanism that links loneliness to RTS. Previous studies have shown an association between loneliness and RS (London et al., 2007; Watson \& Nesdale, 2012) and an association between RS and general threat sensitivity (Berenston et al., 2009; Burkland et al., 2007), but this is the first study to show that loneliness is linked to RTS via RS. Thus, strategies that help a lonely person overcome rejection sensitivity will also help them improve the quality of their romantic relationships and/or maintain newly formed ones. In addition, neither loneliness nor RS were 
Loneliness, RS and RTS in romantic relationships

associated with RIS, indicating that lonely people and/or those sensitive to rejection will not behave in a way that facilitates resolution to problems or conflicts in romantic relationships.

There is little research that has examined the influence of loneliness on romantic relationships, but there is empirical evidence demonstrating that loneliness affects re-affiliation motive and lessens the desire to reconnect with others in peer relationships (e.g. Cacioppo \& Hawkley, 2009; Qualter et al., 2015). The findings in the current study indicate that lonely people behave in a similar way in their romantic relationships to peer relationships (Spithoven

et al., 2017) and are motivated to focus on avoidance of conflict and rejection, rather than being motivated to promote intimacy and growth in the relationship. The association between loneliness and threat sensitivity in romantic relationships may explain why some people are lonely despite being in a romantic relationship (Tornstam, 1992) and why loneliness is linked to poor relationship quality (Deniz et al., 2005; Green et al., 2001; Flora \& Sergin, 2000). Threat sensitivity may also explain why loneliness is associated with inappropriate jealousy (Rotenberg et al., 2001) and relational aggression (Strouch et al., 2004).

\subsection{Age-related differences}

The results in the current study indicate that younger adults are more likely to be motivated to improve connection with their partner if they are in a relationship (i.e. RIS was higher when in a relationship) than older adults. One reason for that difference could be that older adults have been in their current relationships for longer than the younger adults and developed security and trust in the other person over time. Another reason may be that older adults have more security in their relationships because older adults demonstrate lower levels of attachment anxiety (Hudson et al., 2015; Chopik et al., 2014) and greater emotional regulation than younger adults (Nielsen et al, 2008; Silvers et al., 2012). Thus, older adults 
Loneliness, RS and RTS in romantic relationships

may be more able to manage minor disagreements and conflicts in a romantic relationship than younger adults, thus, eliciting more avoidant behaviour.

\subsection{Gender Differences}

Our findings support previous studies showing lower levels of loneliness in those who are in a romantic relationship (Deniz et al., 2005; Green et al., 2001). But, importantly, there was a gender difference in that relationship: for females there were no differences in loneliness based on relationship status, but men were lonelier if not in a relationship. So for women, loneliness may be less about being in an intimate romantic relationship than for men. Friendship research has demonstrated that both men and women gain emotional support from opposite sex relationships (Aukett, Ritchie, \& Mill, 1988; Burleson, 2003), but women are more likely to also make use of same-sex friendships for emotional sharing and support (Aries \& Johnson, 1983; Caldwell \& Peplau, 1982).

\subsection{Strengths and Weakness}

The current study is the first to examine factors that may influence RTS and shows that loneliness and RS are implicated, which is important because it helps to identify people who are more likely to find formation and maintenance of romantic relationships difficult. However, the variance associated with these factors is small, indicating that other factors may play an important role in influencing RTS. Future research should explore other factors that impact RTS, such as relationship quality or length and/or residential status (i.e. living alone or with partner). There may also be other individual differences that impact RTS, such as social anxiety and/or depression. Also, while participants may have been reflecting on their 
Loneliness, RS and RTS in romantic relationships

behaviour in the questionnaire, actual behaviour was not measured and the results gained by using observation methods may be different. Future research could use an observational method to examine differences in threat- related behaviour in couples.

It is important to note that the current study is cross-sectional so it is possible that loneliness leads to threat sensitivity in romantic relationships, but equally possible that if someone behaves in a threat sensitive way in a romantic relationship that they may become lonelier over time. Future research should use a longitudinal design to examine causality in more detail.

\subsection{Applications of the findings}

The findings of the current study are important to help with understanding why some people behave in a threat sensitive way in romantic relationships and implicate loneliness and RS as risk factors for RTS. Thus, lonely people and/or those who are sensitive to rejection may need support to (1) behave in a way that supports a quality romantic relationship and (2) take action that overcomes the threat sensitivity experienced in the relationship. Counsellors and or clinical psychologists supporting lonely people with the formation and maintenance of romantic relationships should focus on supporting the person to avoid negative interpretation of events in the relationship and encourage approach behaviours that will help to resolve difficulties and conflicts, rather than the use of avoidant behaviours which may be more typical for lonely people. The current study indicates that this is particularly important for men who place a significant importance on their romantic partner for their emotional and social support.

\section{Conclusion}


Loneliness, RS and RTS in romantic relationships

The current study is the first to examine risk factors associated with relationship threat sensitivity. Loneliness and rejection sensitivity were associated with relationship threat sensitivity, and rejection sensitivity was shown to be a potential mechanism linking loneliness and relationship threat sensitivity. The findings indicate that both lonely people and those sensitive to rejection may need support with romantic relationships because they will be hypersensitive to threat in the relationship, which could result in a lack of resolution to difficulties experienced in that relationship. Strategies to support lonely people with formation and maintenance of romantic relationships should focus on overcoming threat sensitivity, reducing rejection sensitivity and encourage approach-related behaviours. 
Loneliness, RS and RTS in romantic relationships

\section{References}

Aries, E. J., \& Johnson, F. L. (1983). Close friendship in adulthood: Conversational content between same-sex friends. Sex Roles, 9, 1183-1196. doi:10.1007/BF00303101

Aukett, R., Ritchie, J., \& Mill, K. (1988). Gender differences in friendship patterns. Sex Roles, 19, 57-66. doi:10.1007/BF00292464

Baron, R. M., \& Kenny, D. A. (1986). The moderator-mediator variable distinction in social psychological research: conceptual, strategic, and statistical considerations. Journal of Personality and Social Psychology, 51, 1173-1182.

Berenson, K. R., Gyurak, A., Ayduk, Ö., Downey, G., Garner, M. J., Mogg, K., ... \& Pine, D. S. (2009). Rejection sensitivity and disruption of attention by social threat cues. Journal of research in personality, 43(6), 1064-1072. doi: 10.1016/j.jrp.2009.07.007

Burkland, L J., Eisenberger, N. I., \& Lieberman, M. D. (2007). The face of rejection: Rejection sensitivity moderates dorsal anterior cingulate activity to disapproving facial expressions, Social Neuroscience, 2, 3-4. doi: 10.1080/17470910701391711

Burleson, B. R. (2003). The experience and effects of emotional support: What the study of cultural and gender differences can tell us about close relationships, emotion, and interpersonal communication. Personal Relationships, 10, 1-23. doi: 10.1111/14756811.00033

Cacioppo, J. T., \& Hawkley, L. C. (2009). Perceived social isolation and cognition, Trends in Cognitive Sciences, 13, 447-454. doi: 10.1016/j.tics.2009.06.005

Caldwell, M. A., \& Peplau, L. A. (1982). Sex differences in same-sex friendship. Sex Roles, 8, 721-732. doi:10.1007/BF00287568 
Loneliness, RS and RTS in romantic relationships

Cavallo, J. V., Fitzsimons, G. M., \& Holmes, J. G. (2010). When self-protection overreaches: Relationship-specific threat activates domain-general avoidance motivation. Journal of Experimental Social Psychology, 46, 1-8. doi:10.1016/j.jesp.2009.07.007

Deniz, M., Hamarta, E., \& Ari, R. (2005). An investigation of social skills and loneliness levels of university students with respect to their attachment styles in a sample of Turkish students. Social Behavior and Personality: An international journal, 33, 1932. doi: 10.2224/sbp.2005.33.1.19

Dewitte, M., \& De Houwer, J. (2008). Adult attachment and attention to positive and negative emotional face expressions. Journal of Research in Personality, 42, 498-505. doi:10.1016/j.jrp.2007.07.010

Downey, G., \& Feldman, S. I. (1996). Implications of Rejection Sensitivity for Intimate Relationships. Journal of Personality and Social Psychology, 70, 1327-1343.doi: 10.1037/0022-3514.70.6.1327

Eisenberger, N. I. (2013). Social ties and health: a social neuroscience perspective. Current Opinion in Neurobiology, 23, 407-413. doi: 10.1016/j.conb.2013.01.006

Flora, J., \& Segrin, C. (2000). Relationship development in dating couples: Implications for relational satisfaction and loneliness. Journal of Personal and Social Relationships, 17, 811-825. doi: 10.1037/pspp0000027

Gable, S. L., \& Impett, E. A. (2012). Approach and avoidance motives and close relationships. Social and Personality Psychology Compass, 6, 95-108. doi: 10.1111/j.17519004.2011.00405.x

Green, L. R., Richardson, D. S., Lago, T., \& Schatten-Jones, E. C. (2001). Network correlates of social and emotional loneliness in young and older adults. Personality and Social Psychology Bulletin, 27, 281-288. 
Loneliness, RS and RTS in romantic relationships

Hayes, A. F. (2009). Beyond Baron and Kenny: Statistical mediation analysis in the new millennium. Communication monographs, 76(4), 408-420. doi:10.1080/03637750903310360

Laurenceau, J-P., Kleinman, B. M., Kaczynski, K. J., \& Carver, C. S. (2010). Assessment of relationship-specific incentive and threat sensitivities: Predicting satisfaction and affect in adult intimate relationships. Psychological Assessment, 22, 407-419. doi: 10.1037/a0019231

Lewittes, H. J. (1989). Just being friendly means a lot-Women, friendship, and aging. Women \& Health, 14, 139-159. doi: 10.1300/J013v14n03_10

London, B., Downey, G., Bonica, C., \& Paltin, I. (2007). Social causes and consequences of rejection sensitivity. Journal of Research on Adolescence, 17, 481-506. doi: 10.1111/j.1532-7795.2007.00531.x

Long, M. V., \& Martin, P. (2000). Personality, relationship closeness, and loneliness of oldest old adults and their children. The Journals of Gerontology Series B: Psychological Sciences and Social Sciences, 55, P311-P319. doi: 10.1093/geronb/55.5.P311

MacKinnon, D. P., Lockwood, C. M., \& Williams, J. (2004). Confidence limits for the indirect effect: Distribution of the product and resampling methods. Multivariate behavioral research, 39(1), 99-128. doi: 10.1207/s15327906mbr3901_4

Nielsen, L., Knutson, B., \& Carstensen, L. L. (2008). Affect dynamics, affective forecasting, and aging. Emotion, 8, 318-330. doi: 10.1037/1528-3542.8.3.318

Perlman, D., \& Peplau, L.A. (1981) Toward a social psychology of loneliness. In Duck, S. \& Gilmour, R. (Eds.) Personal Relationships in Disorder (pp. 31-56). London: Academic Press. 
Loneliness, RS and RTS in romantic relationships

Qualter, P., Vanhalst, J., Harris, R., Van Roekel, E., Lodder, G., Bangee, M., ... \& Verhagen, M. (2015). Loneliness across the life span. Perspectives on Psychological Science, 10, 250-264. doi: 10.1177/1745691615568999

Russell, D. W. (1996). UCLA Loneliness Scale (Version 3): Reliability, validity, and factor structure. Journal of Personality Assessment, 66, 20-40. doi: 10.1207/s15327752jpa6601_2

Rotenberg, K. J., Shewchuk, V., \& Kimberley, T. (2001). Loneliness, sex, romantic jealousy and powerlessness. Journal of Social and Personal Relationships, 18, 55-79.

Shrout, P. E., \& Bolger, N. (2002). Mediation in experimental and nonexperimental studies: new procedures and recommendations. Psychological methods, 7(4), 422. doi: 10.1037//1082-989X.7.4.422

Silvers, J. A.; McRae, K.; Gabrieli, J. D. E.; Gross, J. J.; Remy, K. A.; \& Ochsner, K. N. (2012). Age-related differences in emotional reactivity, regulation, and rejection sensitivity in adolescence. Emotion, 12, 1235-1247. doi: 10.1037/a0028297

Spithoven, A. W. M., Bijttebier, P., \& Goossens, L. (2017). It's all in their mind: A review of information processing bias in lonely individuals. Clinical Psychology Review, 58, 97-114. doi:10.1016/j.cpr.2017.10.003

Storch, E. A., Bagner, D. M., Geffken, G. R., \& Baumeister, A. L. (2004). Association between overt and relational aggression and psychosocial adjustment in undergraduate college students. Violence and victims, 19(6), 689. doi: 10.1891/vivi.19.6.689.6634

Tornstam, L. (1992). Loneliness in marriage. Journal of Social and Personal Relationships, 9, 197-217.

Urry, H. L., \& Gross, J. J. (2010). Emotion regulation in older age. Current Directions in Psychological Science, 19, 352-357. doi: 10.1177/0963721410388395 
Loneliness, RS and RTS in romantic relationships

Vanhalst, J., Goossens, L., Luyckx, K., Scholte, R. H., \& Engels, R. C. (2013). The development of loneliness from mid-to late adolescence: Trajectory classes, personality traits, and psychosocial functioning. Journal of adolescence, 36, 13051312. doi: 10.1016/j.adolescence.2012.04.002

Watson, J., \& Nesdale, D. (2012) Rejection sensitivity, social withdrawal, and loneliness in young adults. Journal of Applied Social Psychology, 42, 1984-2005. doi:

10.1111/j.1559-1816.2012.00927.x 
Loneliness, RS and RTS in romantic relationships

Table 1. Descriptive statistics

\begin{tabular}{|c|c|c|c|c|c|c|c|c|c|}
\hline & \multicolumn{4}{|c|}{ In a romantic relationship } & \multicolumn{4}{|c|}{ Not in a romantic relationship } & \multirow[t]{3}{*}{ ANOVA } \\
\hline & \multicolumn{2}{|c|}{ 18-35years } & \multicolumn{2}{|c|}{ Over 35 years } & \multicolumn{2}{|c|}{ 18-35 years } & \multicolumn{2}{|c|}{ Over 35 years } & \\
\hline & $\mathrm{M}$ & SD & $\mathrm{M}$ & SD & $\mathrm{M}$ & SD & $\mathrm{M}$ & SD & \\
\hline Loneliness & 38.76 & 9.64 & 40.99 & 11.35 & 42.20 & 11.16 & 46.86 & 9.90 & 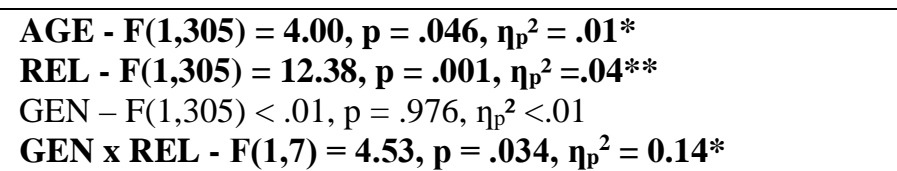 \\
\hline $\begin{array}{l}\text { Rejection } \\
\text { sensitivity }\end{array}$ & 8.75 & 5.36 & 8.90 & 5.10 & 9.14 & 4.43 & 10.94 & 6.01 & 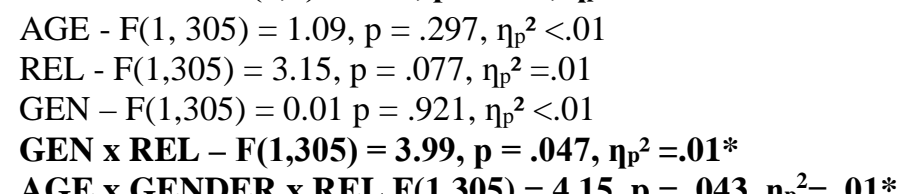 \\
\hline $\begin{array}{l}\text { Relationship } \\
\text { incentive } \\
\text { sensitivity }\end{array}$ & 3.48 & 0.44 & 3.33 & 0.56 & 3.26 & 0.60 & 3.42 & 0.46 & $\begin{array}{l}\text { AGE }-\mathrm{F}(1,305)=0.02, \mathrm{p}=.886, \eta^{2}<.01 \\
\mathrm{REL}-\mathrm{F}(1,305)=0.74, \mathrm{p}=.391, \eta_{\mathrm{p}^{2}}<.01 \\
\mathrm{GEN}-\mathrm{F}(1,305)<.01, \mathrm{p} .953, \eta_{\mathrm{p}}<.01 \\
\text { AGE } \mathbf{x} \mathbf{R E L}-\mathbf{F}(\mathbf{1}, \mathbf{3 0 5})=\mathbf{3 . 8 9}, \mathbf{p}=\mathbf{. 0 5 0}, \mathbf{\eta}_{\mathrm{p}}{ }^{2}=. \mathbf{0 1} *\end{array}$ \\
\hline $\begin{array}{l}\text { Relationship } \\
\text { threat } \\
\text { sensitivity }\end{array}$ & 3.07 & 0.69 & 3.04 & 0.64 & 3.04 & 0.67 & 3.10 & 0.73 & $\begin{array}{l}\text { AGE }-\mathrm{F}(1,305)=0.33, \mathrm{p}=.567, \eta_{\mathrm{p}}^{2}<.01 \\
\mathrm{REL}-\mathrm{F}(1,305)=0.01, \mathrm{p}=.911, \mathrm{n}_{\mathrm{p}}^{2}<.01 \\
\mathrm{GEN}-\mathrm{F}(1,305)=2.18, \mathrm{p}=.141, \eta_{\mathrm{p}}<.01\end{array}$ \\
\hline
\end{tabular}

Note: **significant at $\mathrm{p}<.01$ level, *significant at $\mathrm{p}<.05$ level; REL = Relationship status; GEN = gender; All main effects are reported in the table, with only significant interactions included 
Loneliness, RS and RTS in romantic relationships

Table 2. Correlations between study variables

\begin{tabular}{|c|c|c|c|c|c|c|c|c|c|}
\hline & \multicolumn{3}{|c|}{ All Participants } & \multicolumn{3}{|c|}{ 18-35 years } & \multicolumn{3}{|c|}{35 years and over } \\
\hline & 2. & 3. & 4. & 2. & 3. & 4. & 2. & 3. & 4. \\
\hline 1. Loneliness & $.55 * *$ & -.10 & $.22 * *$ & $.49 * *$ & -.10 & $.26 * *$ & $.63^{* *}$ & -.10 & $.18 *$ \\
\hline 2. RS & & -.07 & $.28 * *$ & & -.10 & $.24 *$ & & -.13 & $.24 * *$ \\
\hline 3. RIS & & & $.43 * *$ & & & $.41 * *$ & & & $.46^{* *}$ \\
\hline 4. RTS & & & & & & & & & \\
\hline
\end{tabular}

Note: **significant at $\mathrm{p}<.001$ level, *significant at $\mathrm{p}<.05$ level; RS = rejection sensivity; RIS = Relationship Incentive sensitivity; RTS = Relationship threat sensitivity 
Loneliness, RS and RTS in romantic relationships

Table 3. Multiple regression analysis with relationship threat sensitivity as the dependent variable

\begin{tabular}{|c|c|c|c|c|c|c|c|c|c|}
\hline & \multicolumn{3}{|c|}{ All Participants } & \multicolumn{3}{|c|}{ 18-35 years } & \multicolumn{3}{|c|}{35 years and over } \\
\hline & B & SE B & $\mathrm{B}$ & $\mathrm{B}$ & SE B & $\beta$ & $\mathrm{B}$ & SE B & $\beta$ \\
\hline Loneliness & .01 & .01 & .08 & $<.01$ & .01 & .14 & $<.01$ & $<.01$ & .04 \\
\hline $\begin{array}{l}\text { Rejection } \\
\text { sensitivity }\end{array}$ & .03 & .01 & $.23 * * *$ & .04 & .01 & $.25^{* *}$ & .03 & .01 & $.22 *$ \\
\hline ANOVA & \multicolumn{3}{|c|}{$\begin{array}{l}\mathrm{F}(2,311)=17.91, \mathrm{p}<.001 \\
\mathrm{R}^{2}=.08, \text { Adj } \mathrm{R}^{2}=.08\end{array}$} & \multicolumn{3}{|c|}{$\begin{array}{l}\mathrm{F}(2,163)=10.66, \mathrm{p}<.001 \\
\mathrm{R}^{2}=.12, \text { Adj } \mathrm{R}^{2}=.11\end{array}$} & \multicolumn{3}{|c|}{$\begin{array}{l}\mathrm{F}(2,147)=4.83, \mathrm{p}=.009 \\
\mathrm{R}^{2}=.06, \text { Adj } \mathrm{R}^{2}=.05\end{array}$} \\
\hline
\end{tabular}


Loneliness, RS and RTS in romantic relationships

Table 4. Hierarchical regression analysis on Relationship Threat Sensitivity

\begin{tabular}{lllllllll}
\hline & Step & $\mathrm{B}$ & $\mathrm{SE}$ & $\beta$ & $\mathrm{t}$ & $\mathrm{p}$ & Adj R $^{2}$ & $\mathrm{p}$ \\
\hline Constant & 1 & 2.55 & 0.14 & & & & & \\
Loneliness & 1 & 0.01 & 0.00 & 0.09 & 1.36 & 0.175 & & \\
$\begin{array}{l}\text { Rejection } \\
\text { sensitivity }\end{array}$ & 1 & 0.30 & 0.01 & 0.23 & 3.60 & 0.000 & & \\
& & & & & & & & \\
Constant & 2 & 2.55 & 0.14 & & & & 0.080 & $<.001$ \\
$\begin{array}{l}\text { Loneliness } \\
\text { Rejection }\end{array}$ & 2 & 0.01 & 0.04 & 0.90 & 1.38 & 0.167 & & \\
$\begin{array}{l}\text { Sensitivity } \\
\text { Loneliness BY }\end{array}$ & 2 & 0.03 & 0.10 & 0.22 & 2.98 & 0.003 & & \\
rejection sensitivity & 2 & 0.00 & 0.001 & 0.24 & 0.38 & 0.706 & & \\
& & & & & & & & \\
\end{tabular}


Loneliness, RS and RTS in romantic relationships

Figure 1 Mediation model of loneliness and rejection sensitivity to relationship threat sensitivity

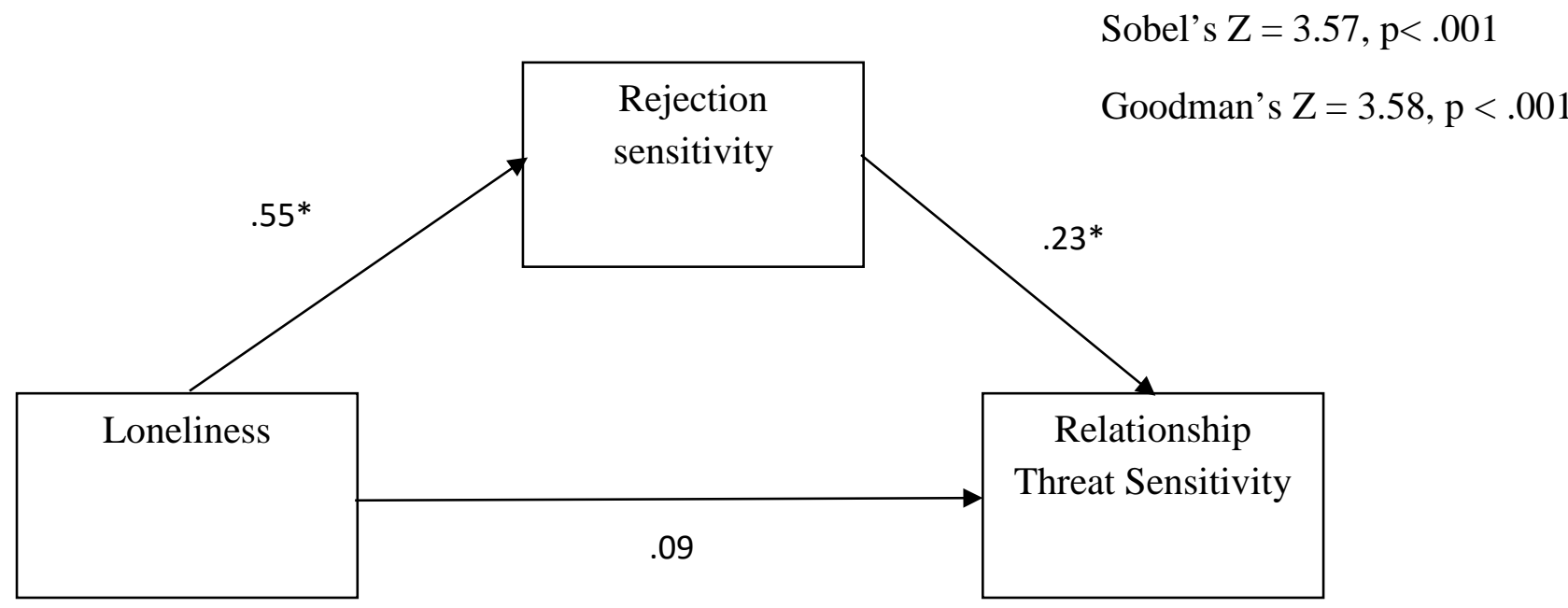

\begin{tabular}{|c|c|c|}
\hline & & $\begin{array}{c}\text { Relationship } \\
\text { Threat Sensitivity }\end{array}$ \\
\cline { 2 - 3 } & $.22^{*}$ & \\
\hline
\end{tabular}

* significant at $\mathrm{p}<.001$ 